\title{
CÂNCER DO COLO DO ÚTERO: PERFIL DE MULHERES QUE BUSCAM A PREVENÇÃO.
}

\author{
Emily da Cruz Lima ${ }^{1}$; Rosana Oliveira de Melo $^{2}$ \\ 1. Bolsista PIBIC/CNPq, Graduando em Enfermagem, Universidade Estadual de Feira de Santana, e-mail: \\ emilylima18@hotmail.com \\ 2. Rosana Oliveira de Melo, Departamento de saúde, Universidade Estadual de Feira de Santana, e-mail: \\ rosanaenfmelo@gmail.com
}

PALAVRAS-CHAVE: Câncer do Colo do Útero; Perfil de Saúde; Enfermagem.

\section{INTRODUÇÃO}

De acordo com o Instituto Nacional de Câncer (INCA) o câncer do colo do útero é o segundo tipo de tumor mais incidente entre as mulheres, e representa a segunda causa de morte da população feminina por câncer no Brasil (INCA, 2016).

Apesar das grandes taxas de mortalidade, este tipo de câncer apresenta alto potencial de prevenção e cura quando diagnosticado e tratado precocemente, chegando perto de $100 \%$, podendo ser tratado em nível ambulatorial em cerca de $80 \%$ dos casos (CASARIN, PICCOLI, 2011). Isto ocorre através dos programas de rastreamento ou screening sistemático da população feminina, por meio do exame citológico do colo do útero, também conhecido como exame de Papanicolaou, que se caracteriza como uma estratégia pública efetiva, segura e de baixo custo para detecção precoce desse tipo de câncer (ALBUQUERQUE, 2009).

Apesar de ser um exame reconhecido como uma técnica efetiva e eficaz, sua cobertura ainda não é suficiente, alguns dados mostram que não houve queda dos índices de mortalidade por câncer cervical nos últimos vinte anos (CASARIN, PICCOLI, 2011).

Portanto, este estudo fornece fundamentações teóricas importantes para descrever o perfil das mulheres que buscam a prevenção do câncer do colo do útero em uma unidade de referência do interior da Bahia, com o objetivo de aprimorar as ações preventivas do câncer do colo do útero para a população atendida e consequentemente, favorecer a detecção precoce das lesões precursoras da doença em estágios iniciais, através da redução dos índices de morbimortalidade da doença.

Esta pesquisa teve como objetivo geral caracterizar o perfil de mulheres atendidas em um Centro de Referência na Bahia através da análise da requisição de exame citopatológico do colo do útero.

\section{MATERIAL E MÉTODOS}

Estudo do tipo descritivo, exploratório e quantitativo, recorte do relatório final da Iniciação Cientifica. Realizado no município de Feira de Santana, no Centro Municipal de Prevenção ao Câncer (CMPC). Composto por dados secundários, obtidos das requisições de citopatológico do colo do útero de mulheres atendidas no CMPC, no ano de 2016. Utilizouse a técnica de análise documental para a coleta dos dados. Para aplicação desta, foi criado um formulário online, previamente elaborado pela pesquisadora.

Elegeu-se como critério de inclusão, requisições preenchidas com dados de identificação legíveis. E como critérios de exclusão requisições com dados de identificação ilegíveis ou danificados, de forma que não permitisse a visualização pelo pesquisador, tais como rasuras e manchas. 
Foi realizada uma análise estatística descritiva dos dados. Os dados foram tabulados em planilhas eletrônicas e analisados através do programa Statistical Package for the Social Sciences (SPSS), na versão 22.0. A partir disso, foram retiradas as frequências absolutas e percentagem visando o alcance dos objetivos do trabalho.

O projeto foi aprovado pelo Comitê de Ética em Pesquisa com Seres Humanos da Universidade Estadual de Feira de Santana (CEP-UEFS), parecer nº 2.386.774.

\section{RESULTADOS E DISCUSSÃO}

Foram analisadas 2.844 fichas de requisições de exames citopatológico, de mulheres atendidas no CMPC no ano de 2016. Observou-se que a faixa etária predominante foi de 40 a 49 anos, com nível de escolaridade $1^{\circ}$ grau incompleto, residentes no município sede do estudo.

Com relação às impressões registradas no exame clinico do Papanicolaou, observou-se que $69,3 \%$ das mulheres apresentaram o colo do útero normal à inspeção do profissional durante a coleta.

O útero é um órgão que pertence ao sistema reprodutor feminino e, é dividido em duas partes: corpo e colo. O colo do útero sem alterações é revestido por células epiteliais pavimentosas dispostas de forma ordenada. O revestimento externo, do mesmo, é denominado ectocérvice e o interno endocérvice, estes são unidos pela junção escamocolunar (JEC). Quando a mulher desenvolve câncer do colo do útero é neste local que, na maioria das vezes, ocorre o desenvolvimento desta doença. Diante da presença do câncer, ocorre um crescimento desordenado de células que se desenvolvem nos epitélios de revestimento da endocérvice e ectocérvice do colo do útero (TELES; ALVES; FERRARI, 2013).

$\mathrm{O}$ colo do útero pode ainda estar ausente diante de algumas situações como, por exemplo, a histerectomia. Para mulheres histerectomizadas o Inca (2016) recomenda que, quando a histerectomia total foi decorrente de lesões benignas e não apresentam história previa de diagnóstico ou nunca realizaram tratamento de lesões precursoras do câncer do colo uterino, podem ser excluídas do rastreamento. No entanto, devem apresentar exames prévios sem alterações. Por outro lado, quando se tratar de histerectomia decorrente de lesão precursora ou câncer do colo do útero, a paciente deverá ser seguida com base no tipo de lesão tratada.

Ainda de acordo com as impressões registradas no exame clinico do Papanicolaou, 91,5\% as mulheres não apresentaram sinais sugestivos de infecções sexualmente transmissíveis (IST). Apesar da maioria não apresentar IST sabe-se que infecções como citomegalovírus, herpes, clamídia e o Papilomavírus Humano (HPV) são fatores de risco para o desenvolvimento de lesão intraepitelial escamosa (BRITO; GALVÃO, 2010). Além disso, a presença da infecção pelo HIV pode ser fator agravante (CASTILLEJO et al., 2016).

Algumas pesquisas apontam maior risco de desenvolver o câncer do colo do útero por mulheres com HIV/AIDS, devido à imunossupressão causada pela mesma. As mulheres que apresentam essas infecções e ainda tem como fatores de risco, histórico de atividades sexuais desprotegidas e história prévia de outra IST, aumentarão as chances de desenvolver esse tipo de câncer (BRITO; GALVÃO, 2010).

Dentre as IST, o HPV constitui-se a infecção mais comum. O tipo oncogênico é considerado o principal fator de risco para o desenvolvimento do câncer cervical. "Todos os anos, estima-se que 17.600 mulheres e 9.300 homens são diagnosticados com um câncer causado HPV". (KIM; WASHBURN; RAYMOND, 2016, p. 34)

A presença do HPV em pacientes soropositivas acarreta em maior risco de desenvolver a neoplasia intraepitelial cervical. Estudos demonstram maior prevalência do 
HPV em pacientes soropositivas quando comparadas as soronegativas (BRITO; GALVÃO, 2010).

Há evidencias cientificas na literatura em relação à associação entre o HPV e o câncer do colo do útero. Cerca de $80 \%$ das mulheres em fase reprodutiva irão contrair o HPV ao longo do tempo, no entanto, somente a menor parcela dessas irá adquirir a infeção causada pelo vírus oncogênico, que acarretará no surgimento de lesões precursoras. Isto indica que outros fatores também são responsáveis pelo desenvolvimento do câncer do colo do útero, além das particularidades da infecção pelo HPV (tipo e carga viral, infecção única ou múltipla) como à imunidade, a genética, o comportamento sexual, a idade e o tabagismo (BRASIL, 2013).

Tabela 1: Distribuição da amostra de acordo a inspeção do colo do útero. Feira de Santana, 2017.

\begin{tabular}{lcc}
\hline VARIÁVEIS & $\mathbf{N}^{\mathbf{o}}$ & $\mathbf{\%}$ \\
\hline Inspeção do colo do útero* & 1886 & 69,3 \\
Normal & 177 & 6,5 \\
Ausente & 576 & 21,2 \\
Alterado & 84 & 3,1 \\
Colo não visualizado & & \\
& & \\
Sinais sugestivos de doenças sexualmente transmissíveis** & 222 & 8,5 \\
Sim & 2385 & 91,5 \\
Não & \\
\hline
\end{tabular}

Fonte: Requisições de exames citopatológico. Centro Municipal de Prevenção do Câncer Romilda Maltez.

*121 fichas não tinham tal dado preenchido.

** 237 fichas não tinham tal dado preenchido.

\section{CONSIDERAÇÕES FINAIS}

O presente estudo encontrou como limitação a não disposição dos dados das requisições do citopatológico em sistemas informatizados, bem como a indisponibilidade de todas as requisições do período estudado na unidade de construção da pesquisa. A realização desse estudo salienta a importância do preenchimento de todos os dados da ficha de requisição de citopatológico do colo do útero, bem como de todos os impressos solicitados pelo Ministério da Saúde. O registro de tais dados possibilita maior fidedignidade nos resultados das pesquisas, fazendo com que as intervenções possam ser implantadas com mais efetividade e que sejam o retrato das reais necessidades da população.

\section{REFERENCIAS}

ALBUQUERQUE, K. M. et al. Cobertura do teste de Papanicolaou e fatores associados à não-realização: um olhar sobre o Programa de Prevenção do Câncer do Colo do Útero em Pernambuco, Brasil. Caderno de Saúde Pública, Rio de Janeiro, 25 Sup 2:S301-S309, 2009 BRASIL. Ministério da Saúde. Controle dos cânceres do colo do útero e da mama. Caderno de Atenção Básico, nº 13, Brasília, 2013.

BRITO, D.M.S; GALVÃO, M.T.G. Fatores de risco para câncer de colo uterino em mulheres com HIV. Revista Rede de Enfermagem do Nordeste, Fortaleza, v. 11, n. 1, p. 191-199, jan./mar.2010. 
CASTILlEJO, et al. Recomendaciones de prevención del cáncer. Actualización 2016. Aten Primaria, p. 39-59, n. 48, 2016.

CASARIN, M. R.; PICCOLI, J. C. E. Educação em Saúde para Prevenção do Câncer de Colo do Útero em Mulheres do Município de Santo Ângelo/RS. Ciências e Saúde Coletiva, v.16, n.9, 2011.

INSTITUTO NACIONAL DO CÂNCER. MINISTÉRIO DA SAÚDE. Estimativa/2016: Incidência de Câncer no Brasil / Instituto Nacional de Câncer José Alencar Gomes da Silva, Coordenação de Prevenção e Vigilância. Rio de Janeiro: INCA, 2016.

KIM; WASHBURN; RAYMOND. Human Papillomavirus (HPV) Vaccination Coverage among Rhode Island Adolescents, 2008-2016. Rhode Island Medical Journal, 2016.

TELES, C.C.G.D; ALVES,E.D; FERRARI,R. Lesões precursoras para o câncer do colo uterino e seus fatores de risco: estudo reflexivo. Revista de enfermagem da UFPE on line., Recife, v.7, p.5733-41, set., 2013 